\title{
René Théophile Hyacinthe Laënnec (1781-1826). Two hundred years of the stethoscope. A brief overview
}

\author{
Alejandro Donoso F., M.D. ${ }^{a}$ and Daniela Arriagada S., M.D. ${ }^{a}$
}

\begin{abstract}
Two hundred years have passed since the publication that revealed the clinical use of the stethoscope. René Théophile Hyacinthe Laënnec published it in 1819. Laënnec spent his childhood in the social effervescence of the French Revolution and studied medicine in Paris, where he graduated in 1804. His clinical experience at Necker Hospital peaked with the invention of the stethoscope in 1816. Three years later, he published his masterpiece De L'Auscultation Médiate, which underlined a more rational clinical-pathological approach, especially in the understanding of cardiopulmonary diseases. Undoubtedly, Laënnec revolutionized medicine by perfecting the art of thoracic semiology, which allowed him to translate the sounds he heard into an image that could be visualized.

In the bicentennial of the invention of such fundamental milestone in modern medicine, the purpose of this article is to go over its history. Key words: René Théophile Hyacinthe Laënnec, stethoscopes, auscultation, history of medicine.
\end{abstract}

http:/ / dx.doi.org/10.5546/ aap.2020.eng.e444

To cite: Donoso F A, Arriagada S D. René Théophile Hyacinthe Laënnec (1781-1826). Two hundred years of the stethoscope. A brief overview. Arch Argent Pediatr 2020;118(5):e444-e448.

\section{INTRODUCTION}

It was 1816 and, most likely, the

a. Unit of Pediatric Critical Patients, Hospital Dra. Eloísa Díaz I., La Florida, Santiago, Chile.

E-mail address:

Alejandro Donoso F., M.D.: adonosofuentes@gmail. com

Funding:

None.

Conflict of interest: None.

Received: 11-28-2019 Accepted: 1-27-2020 action of the heart in a manner much more clear and distinct than I had ever been able to do by the immediate application of the ear."1 Thus the stethoscope was invented. ${ }^{2}$

At present, even with its limitations and the growing demand for complex imaging techniques, its use as the main instrument in clinical diagnosis has not been surpassed or abandoned. A stethoscope is a critical piece of our equipment and, more than anything else, it accounts for a symbol of the medical profession in the eyes of society. ${ }^{2}$

\section{RENÉ THÉOPHILE HYACINTHE}

\section{LAËNNEC (1781-1826)}

Early years: Quimper and Nantes

René Laënnec (Figure 1) was born on February $17^{\text {th }}, 1781$ in Brittany (France), in the beautiful town of Quimper, with its typical architecture full of facades with timber frameworks and a labyrinth of narrow streets, lapped by the waters of the Odet and Steir rivers (actually, the Breton word for Quimper is kemper, meaning "confluence").

He was the elder of three siblings. At 5 years old, his mother died while giving birth to her fourth child, who also died soon after birth. His father, a lawyer known for squandering, was not able to properly look after his children, so he decided to send two of them (René and Michaud) to live with their uncle Guillaume François Laënnec (1744-1822), the Dean of the School of Medicine of the University of Nantes. In this way, Laënnec arrived in Nantes at 7 years old, in the midst of the French Revolution. There he learned Latin, Greek, and English, while also writing poetry, playing the flute, and carving wood. 
During his childhood, his admiration for his uncle grew every day, which undoubtedly influenced him to choose medicine as his professional career. At 14 years old, he was helping to take care of ill and wounded people at the renowned Hôtel-Dieu de Nantes Hospital and, by 18 years old, he was appointed a thirdclass surgeon (performing phlebotomies, wound dressing, and minor surgeries) at the city's military hospital. ${ }^{3}$ In spite of growing up in times of turmoil, Laënnec was eager to continue his studies in Paris, but his plans were scarcely supported by his father (who had remarried); however, his uncle Guillaume fully backed him. Thus, at 20 years old, he decided to leave Nantes.

\section{Studies in Paris and return to Brittany}

Laënnec and his brother moved to the Latin neighborhood, and he started studying at the School of Medicine of Paris, Europe's leading clinical research center back then. He was the disciple of famous professors, including Guillaume Dupuytren (1777-1835), Xavier Bichat (1771-1802), Jean-Nicolas Corvisart-Desmarets (1755-1821, Napoleon's physician), and GaspardLaurent Bayle (1774-1816). Bayle and Laënnec became close friends in the following years.

Figure 1. René Théophile Hyacinthe Laënnec (1781-1826)

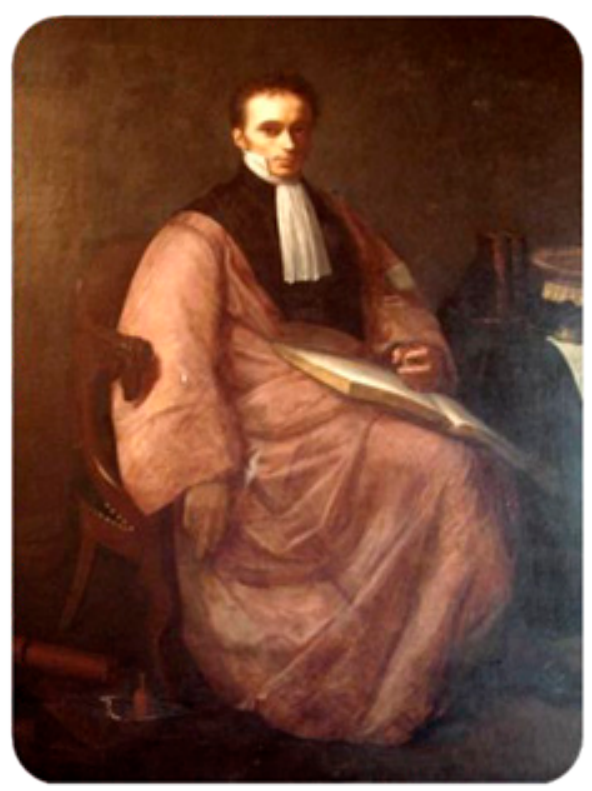

Portrait of René Théophile Hyacinthe Laënnec. Paul Dubois, 1854 (posthumous).

Museum of the History of Medicine, Paris.
Finally, at 23 years old, he graduated as a doctor of medicine with a dissertation titled Propositions sur la Doctrine d'Hippocrate, relativement à la médecine pratique.

In the following years, Laënnec combined his clinical practice with teaching, writing documents, and editing medical journals and books. In this way, his reputation increased progressively across Paris. Unfortunately, something interfered with his successful work life: his poor health. From a young age, he had suffered events classified as "asthma attacks". ${ }^{2}$ In addition, phthisis (which was named tuberculosis only in 1839 by naturalist and physician Johann Lukas Schönlein [17931864]) was always part of his life given that his mother, his brother Michaud (who died in 1810), his uncle, his professor Bichat, and his close friend Bayle died from this condition.

By the time he graduated, he was already very frail because he had been exposed to a large number of phthisic patients and their necropsies. In addition, his scrawny and small build (he was $1.6 \mathrm{~m}$ tall) aggravated his "notoriously ill" appearance. Thus, towards 1814, he was in very poor health, so he had to return to Brittany, to his manor of Kerlouanec, looking for peace and rest.

\section{STETHOSCOPE INVENTION}

Necker Hospital, in Paris, was the home to Laënnec's most important contributions to medicine. The hospital had been founded in 1778 by Madame Necker after remodeling an old monastery. ${ }^{3,4}$

Bayle was chef de service but, after his death in 1816, Laënnec succeeded him and became responsible for 100 hospital beds, which was an inexhaustible source of clinical material for his research on chest diseases. Specifically, he correlated the physical signs observed with the stethoscope with the particular anatomopathological findings found in the necropsies he performed himself. In this way, he described pulmonary consumption, pneumonia, bronchiectasis, emphysema, and pneumothorax, among other diseases, and coined several semiological terms related to the lungs (see below). ${ }^{3}$

In those days, the heart and lungs assessment was based on "direct or immediate auscultation" (placing the ear on the patient's chest). This modality, existing since Hippocrates' times (c. 460 BC - c. 370 BC), was not commonly practiced but was more useful in the auscultation of the respiratory system than in the cardiac 
examination, because it did not help to find the sound from a small precordial area. The other modality used was percussion, introduced by Austrian physician Leopold Auenbrugger, in 1761, in his book Inventum Novum. ${ }^{2,3,5}$ However, it had gone relatively unnoticed until his work was translated into French by Corvisart in 1808, thus influencing physicians looking for methods to improve their diagnostic techniques.

Laënnec expressed his opinion on "direct auscultation": "Direct auscultation was as uncomfortable for the doctor as it was for the patient, disgust in itself making it impracticable in hospitals. It was not suitable for most women, and for some, their own breast size was a physical obstacle to using this method". ${ }^{3}$

One day, Laënnec was summoned to examine a young woman with cardiac symptoms but given her great degree of fatness, percussion and palpation were of no avail. In addition, according to him, direct auscultation was "inadmissible by the age and sex of the patient". Therefore, he recalled an acoustic phenomenon that indicated an augmented impression of sound when conveyed through certain solid bodies ("as when we hear the scratch of a pin at one end of a piece of wood on applying the ear on the opposite end"). So, he decided to firmly roll a quire of paper into a sort of cylinder and applied one end to the patient's chest and the other to his ear. To his surprise and delight, he perceived the heartbeat in a much clearer manner., ${ }^{2,3}$

From that moment, Laënnec imagined what this technique may furnish because it would allow to "better ascertain the character of any sound produced by the motion of all the thoracic viscera". This commenced a series of observations at Necker Hospital, which led him to discover a set of new signs of diseases, allowing him to significantly improve his diagnostic ability of diseases of the lungs, heart, and pleura. ${ }^{6}$

Continuing with his research, Laënnec focused on designing different prototypes (remember carving was one of his hobbies) and finally built a cylinder of wood $(25 \mathrm{~cm} \times 2.5 \mathrm{~cm})$, perforated in its center longitudinally that could be separated into two parts, for the benefit of being more easily carried. He designated this instrument "the cylinder" or "stethoscope." The latter derived from two Greek words: stêthos "chest" and skopein "to look at." Besides, the term auscultation, also coined by Laënnec, came from the Latin auscultãre and means "to listen carefully"7 (Figure 2).

However, the idea that Laënnec's inspiration for inventing this instrument came while he was walking one morning around the Tuilerie Gardens and he saw two boys "playing at either end of a long beam of wood. One of them would scratch the end of the log with a pin and the other could hear the sound at the other end" ${ }^{2}$ may be fake. $^{3}$

\section{Publication of De l'Auscultation Médiate, his masterpiece}

Using his new instrument, and thanks to his tireless work and commitment (seeing approximately 3000 patients), Laënnec managed to correlate the physical findings of a sick lung and heart with those observed in necropsies, thus allowing him to classify cardiopulmonary disorders based on pathological and clinical guidelines. Finally, after three years of thorough research, he described his outcomes in his work De l'Auscultation Médiate, ou Traité du Diagnostic des Maladies des Poumons et du Coeur, published in August $1819,{ }^{2,3}$ in two volumes, with an initial run of 3500 copies (Figure 3). Its price was 13 francs and it was accompanied by a wood stethoscope for an additional 2.5 francs. ${ }^{3}$

Acceptance among the French medical community was initially poor, with few copies sold and, although his teachings were embraced, the stethoscope was still considered by many a topic of joke or mockery. Notwithstanding this,

FIGURE 2. Laënnec's stethoscope or cylinder

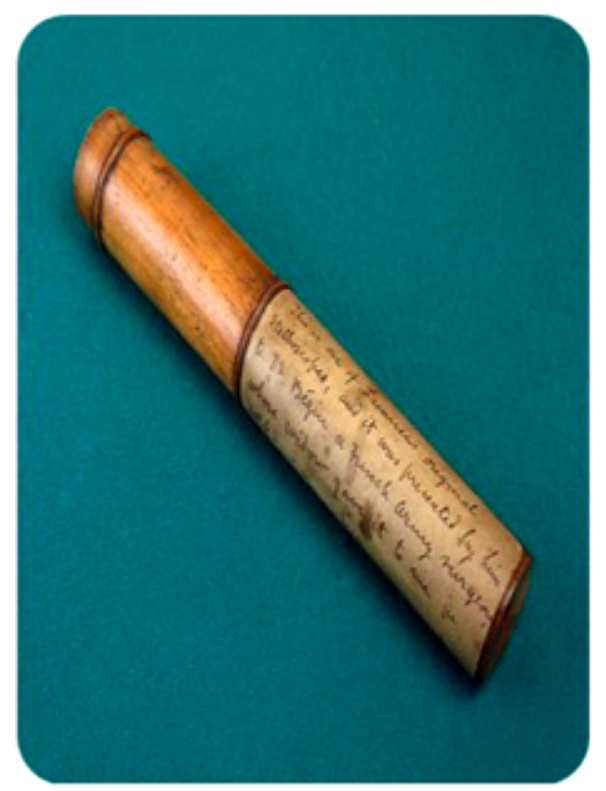

About 1820. Science Museum, London. 
Paris soon became a center of attraction and pilgrimage for European students and physicians, including, in particular, a young man called Thomas Hodgkin (1798-1866), who learned how to use this new diagnostic instrument and took it back to London, where he demonstrated its use in a conference held at Guy's Hospital in 1822. During the conference, the most experienced physicians were unimpressed by this peculiar cylinder and used the stethoscope as a flowerpot. However, students removed the flowers and started using the new instrument to examine one another. ${ }^{8}$

Laënnec's work was translated into English by Scottish physician John Forbes (1787-1861) in 1821 and, after the publication of the second edition (1826), skepticism about the stethoscope reversed progressively and it became a standard, universally accepted practice. In 1851, Irish physician Arthur Leared (1822-1879) invented the binaural stethoscope; and the stethoscope just as we know it today was perfected for commercial production in 1852 by New Yorker George Cammann (1804-1863). ${ }^{7}$

Figure 3. Cover of De L'Auscultation Médiate, ou Traité du Diagnostic des Maladies des Poumons et du Coeur (On Mediate Auscultation, or Treatise on the Diagnosis of the Diseases of the Lungs and Heart). Published in Paris, in 1819

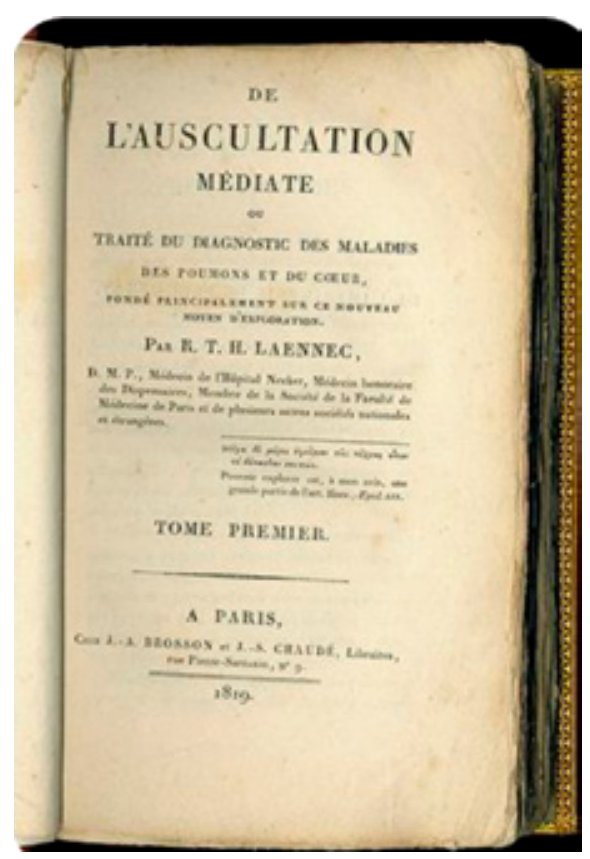

\section{Semiological classification of pulmonary auscultation as per Laënnec and other contributions to medicine}

The pathological and clinical guidelines developed by Laënnec were the basis for almost all the nomenclature for auscultation; many terms are still used nowadays. He basically described normal sounds (lung or vesicular and bronchial) and adventitious sounds or bruits étrangers, such as crepitant (described as "the sound of salt crackling when roasted in an evaporation dish"), gurgling, snoring, whistling or hissing, and crackling. He detailed pectoriloquism, meaning "speech from the chest," which according to its anatomical correlation corresponded to a sign of lung cavitation, in addition to egophony and pleural friction, among other findings.

Initially, Laënnec used the French term râles (rattles), but later decided to change it because he was concerned that it might frighten his patients when discussing his findings due to its resemblance to "le râle de la mort" or "death rattle". Thus, in the preface of the second edition of his treatise, he pointed out that he chose to use the Latin equivalent rhonchus. ${ }^{3}$

Contrary to his detailed semiology of the lungs, his classification of heart sounds was not as complete because, in those times, there was little knowledge of the cardiovascular physiology. Laënnec described the first and second heart sounds (although mistakenly because he attributed the first sound to the ventricular systole and the second one, to the atrial systole), and was also able to tell hypertrophy from cavity dilation and recognized ectopic heartbeats and murmurs resulting from heart valve diseases. However, he did not describe pericardial rub in detail. ${ }^{9}$

He also explained pulmonary metastases in melanoma patients ${ }^{10}$ and coined the name for this condition. ${ }^{11}$ Finally, he proposed terms for diseases as varied as cirrhosis, phlegm produced in asthma patients, prenatal intracavitary thrombus, spontaneous pneumomediastinum, among others. ${ }^{1,2}$

\section{His later years}

In 1823, Laënnec was selected to become a member of the Royal Academy of Medicine, the same year he retired from Necker Hospital and moved to La Charité Hospital, where he was Professor of Clinical Medicine. The following year, he was made a Knight of the Legion of Honor. He was also the editor of the Journal de Médecine, Chirurgie, et Pharmacie. ${ }^{3}$ 
Putting an end to his bachelorhood, in 1824 he married Madame Jacqueline Argou, his friend and housekeeper. They did not have children. Laënnec continued working in spite of his long and severe fight against phthisis, which he attempted to deny for too long and made him leave Paris back to Kerlouanec. Once there, he asked his nephew Mériadec to listen to his heart with a stethoscope and describe what he heard. The auscultation findings were categorical: paradoxically, he was dying of cavitating pulmonary tuberculosis.

Short before dying, Laënnec bequeathed his scientific publications, his most cherished possessions, and his best legacy, the stethoscope, to Mériadec. ${ }^{12}$ As he lay on his deathbed, he removed his rings and laid them on the table by his bed, pointing out that "Someone would soon have to render me this service; I wish to spare them this painful task". He died on August $13^{\text {th }}$, 1826, aged 45 years. Laënnec was buried in the cemetery on the cliffs near Ploaré, in his beloved Brittany.

\section{DISCUSSION}

In connection with the bicentennial of the publication of De l'Auscultation Médiate, it is imperative to recognize the father of clinical auscultation and, undoubtedly, one of the masters of medicine. ${ }^{3}$ Laënnec's fame is not only due to the invention of the stethoscope and the development of mediate auscultation for the physical examination of the chest, but also to his brilliance when correlating abnormalities observed with their corresponding necropsy findings. In this manner, a paradigm shift started in medicine, from the prevailing approach of humoral pathology (the hypothesis of the imbalance of humors) towards an approach that associated disease with a specific organ. ${ }^{13}$ Laënnec's research was based on clinical observation, his new diagnostic technique, and post-mortem anatomy. All this occurred in the setting of great medical reforms in the postrevolutionary Paris. ${ }^{14}$

Although major changes and technical advances have been made in relation to the development of the stethoscope, ${ }^{7}$ and its actual usefulness in current times has been questioned, ${ }^{15-17}$ it has stood the test of time and remains as the cornerstone of medical diagnosis. Two centuries have passed since Laënnec rolled a quire of paper into a cylinder to hear the chest; however, every time a physician auscultates a patient with a stethoscope, they will continue perpetuating such beautiful story.

\section{REFERENCES}

1. Aguilar Fleitas B. Bicentenario de un símbolo: el estetoscopio. Nacimiento y agonía del examen físico. Rev Urug Cardiol. 2016; 31(3):375-80.

2. Roguin A. Rene Theophile Hyacinthe Laënnec(1781-1826): The Man Behind the Stethoscope. Clin Med Res. 2006; 4(3):230-5.

3. Sakula A. R T H Laënnec $1781-1826$ his life and work: a bicentenary appreciation. Thorax. 1981; 36(2):81-90.

4. SaravíF. Laennec, el método anatomoclínico y la invención del estetoscopio. Parte 1: de Bretaña a París, hasta la gran invención. Rev Médica Univ. 2012; 8(2):1-33.

5. Davies MK, Hollman A. Joseph Leopold Auenbrugger (1722-1809). Heart. 1997; 78(2):102.

6. Kligfield P. Laënnec and the discovery of mediate auscultation. Am J Med. 1981; 70(2):275-8.

7. Montinari MR, Minelli S. The first 200 years of cardiac auscultation and future perspectives. J Multidiscip Healthc. 2019; 12:183-9.

8. Stone MJ. Thomas Hodgkin: medical immortal and uncompromising idealist. Proc (Bayl Univ Med Cent). 2005; 18(4):368-75.

9. Fayssoil A. René Laennec (1781-1826) and the invention of the stethoscope. Am J Cardiol. 2009; 104(5):743-4.

10. Karamanou M, Stratigos AJ, Saridaki Z, Tsoucalas G, et al. René-Théophile-Hyacinthe Laennec (1781-1826) and the description of metastatic pulmonary melanoma. J BUON. 2015; 20(1):354-6.

11. Denkler K, Johnson J. A lost piece of melanoma history. Plast Reconstr Surg. 1999; 104(7):2149-53.

12. Tomos I, Karakatsani A, Manali ED, Papiris SA. Celebrating Two Centuries since the Invention of the Stethoscope. René Théophile Hyacinthe Laënnec (1781-1826). Ann Am Thorac Soc. $2016 ; 13(10): 1667-70$.

13. Kuhn T. The structure of scientific revolutions. $3^{\text {rd }}$ ed. Chicago: University of Chicago Press; 1996.

14. Ackerknecht E. Medicine at the Paris Hospital 1794-1848. Baltimore: The John Hopkins Press; 1967.

15. Hubmayr RD. The times are a-changin': should we hang up the stethoscope? Anesthesiology. 2004; 100(1):1-2.

16. Wilkins RL. Is the stethoscope on the verge of becoming obsolete? Respir Care. 2004; 49(12):1488-9.

17. Marini JJ, Vincent JL, Wischmeyer P, Singer M, et al. Our favorite unproven ideas for future critical care. Crit Care. 2013; 17(Suppl 1): S9. 